\title{
Design of Turbine-Based Rain Measurement System
}

\author{
Hartono, Farzand Abdullatif*, Sugito, and Zaroh Irayani \\ Electronics and Instrumentation Laboratory, Department of Physics, \\ Faculty of Mathematics and Natural Sciences, Universitas Jenderal Soedirman, \\ Jl. Dr.Soeparno No. 61 Karangwangkal Purwokerto 53123, Indonesia. \\ *Corresponding Author: farzand@unsoed.ac.id
}

\begin{abstract}
Rain measurement systems have significantly developed. In this work, a novel modification to commonly used rain measurement systems is developed. It comprises a turbine with an infrared sensor to detect its rotation. The design of the rainfall collecting funnel refers to that of general use. The prototype of the design has been characterized with an artificial rainfall, namely continuously flowing water kept at a certain debit. For characterization purpose, the water debit is gradually changed to simulate variations in rainfalls. Important results based on the characterization are threshold value of $0.01 \mathrm{~mm} / \mathrm{min}$ and average deviation of $1.36 \%$, suggesting that this tool is able to detect even a weak rainfall.
\end{abstract}

Keywords: Rain gauge, rainfall, turbines, infrared, sensor

\section{INTRODUCTION}

Infiltrations of water through rock materials will perturb the stability rock materials lying on impermeable rocks, which forms a sliding surface, and triggers a landslide [1]. The process increases with rainfall level, such that rainfall is one of important contributing factors to lanslides [2]. Being a significant factor triggering a landslide, rain intensity and water infiltrations into soils needs to be continuously monitored. Here we propose a design of simple rainfall monitoring system that can signal impending landslide, built from cheap materials.

Real-time continuous measurement has been widely used to obtain exact values of rain intensity. In such a system observation data will be easily accessible and information will be promptly delivered. An online rain measurement system was developed using a tipping bucket sensor [3-5]. A further development using multisensor tipping-bucket was applied to monitor a microphysical area [6]. Measurements of rain intensity can also be conducted using radar, allowing for image processing. The WSR-88D (Weather Service Radar) is a method that is used for weather monitoring, one of which is rainfall $[7,8]$. Soil moisture measurement is also an important factor in the identification of landslide precursors [9].
Availability of the system poses a problem for real-time continuous rainfall monitoring, particularly in landslide prone areas. Therefore, a simple rainfall measurement system constructed from readily available materials is what is required. In this work a prototype of such a system was built to offer a solution to the problem.

\section{METHODS}

The system consists of three main parts, i.e. collecting funnel, turbine, and infrared sensor and lastly data processing microcontroller (See Fig. 1). The funnel being used is what is generally used in common rain measurement systems. The turbine is $8 \mathrm{~cm}$ in diameter, $2 \mathrm{~cm}$ thick, and has 12 blades. Its rotation is measured using infrared optocoupler and rotary encoder. The last part of the design is data acquisition set, which is Atmega 8535 microcontroller. Embedded with an LCD display, it is used to perform calculations with turbine rotations and convert them into the value of rain intensity displayed on the LCD. 


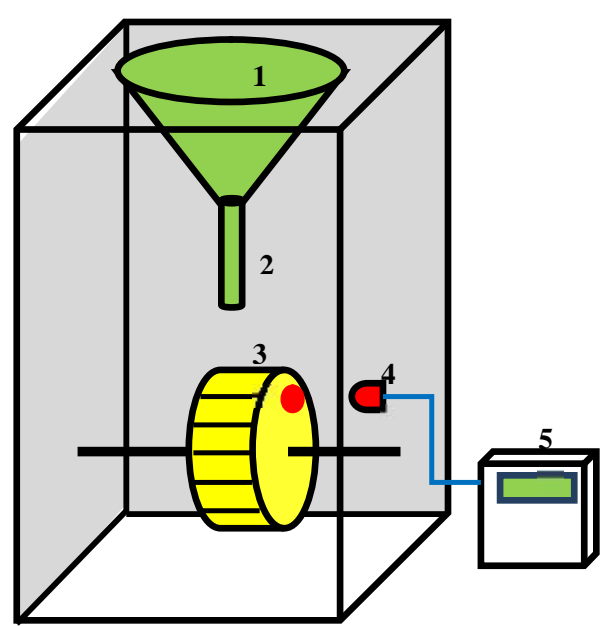

1

Figure 1 Schematic diagram of the apparatus

The last step is finalizing the system by testing and characterization. The test is conducted to examine overall performance of the system. The characterization to identify the threshold, accuracy, and sensitivity was conducted at a laboratory scale using an artificial rainfall. It was running water flowing continuously at a constant debit. The variation in rain intensity was simulated by varying the water debit flown into the system.

\section{RESULTS AND DISCUSSIONS}

The test on the prototype was commenced from the minimum value of rainfall detectable by the system. Response of the system is demonstrated by rotation of the turbine. The test was continued by varying the debit of running water up to 0.39 $\mathrm{mm} /$ minute. The experimental test is given in Table 1.

Table 1 Experimental testing data of the system

\begin{tabular}{rrrr}
\hline No & $\begin{array}{c}\text { Artificial } \\
\text { Rain } \\
\text { Intensity } \\
(\mathbf{m m} / \mathbf{m n t})\end{array}$ & $\begin{array}{c}\text { Mean } \\
\text { RPM }\end{array}$ & $\begin{array}{c}\text { Rain } \\
\text { Intensity } \\
\text { shown by } \\
\text { the sensor } \\
\text { (mm/mnt) }\end{array}$ \\
\hline 1 & 0.015 & 8.35 & 0.009 \\
2 & 0.042 & 14.30 & 0.029 \\
3 & 0.060 & 24.25 & 0.063 \\
4 & 0.090 & 29.30 & 0.080 \\
5 & 0.099 & 41.10 & 0.121 \\
6 & 0.180 & 62.05 & 0.192 \\
7 & 0.255 & 89.45 & 0.285 \\
8 & 0.360 & 104.70 & 0.337 \\
9 & 0.390 & 119.00 & 0.385 \\
\hline
\end{tabular}

The experimental data testing is then plotted into a calibration function for the sensor system shown in Fig. 2.

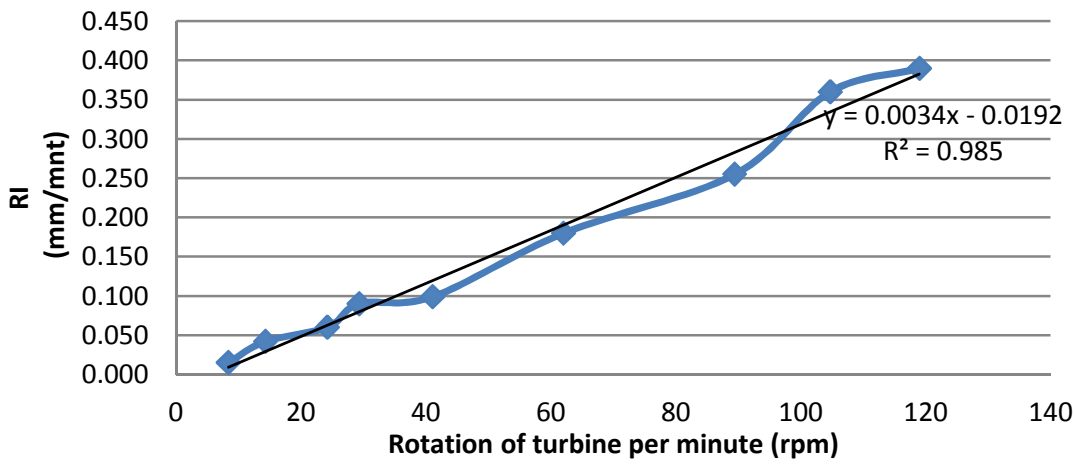

Figure 2 Graph of calibration function of the rainfall measurement system

Based on the graph shown in Figure 2, the calibration function is found to be

$$
y=0.0034 x-0.0192,
$$

where $y$, denotes rain intensity in $\mathrm{mm} /$ minute and $\mathrm{x}$ denotes the number of turbine rotation per minute. The function represents rain intensity as a function of turbine rotation with a slope of $0.0034 \mathrm{~mm} /$ rotation. It implies that every single 
rotation of the turbine corresponds to rain intensity of $0.0034 \mathrm{~mm}$. The gradient of the plot also suggests the sensitivity the sensor system, i.e. 294.12 rotation $/ \mathrm{mm}$. It can also be inferred from the plot that smallest detectable rain intensity (threshold) of the system is 0.01 $\mathrm{mm} /$ minute.

Rain intensity is classified into five levels: very weak ( $<0.02 \mathrm{~mm} /$ minute), weak $(0.02-0.05$ $\mathrm{mm} /$ minute), moderate $(0.05-0.25 \mathrm{~mm} /$ minute), heavy (0.05-1 mm/minute), and very heavy (> 1 $\mathrm{mm} /$ minute). According to the classification, the system is able to detect rainfalls ranging from weak to heavy.

Another test was conducted on displacement of the measured value of rain intensity from its true value. The minimum and maximum is found to be $0.325 \%$ and $2.993 \%$, respectively, with average displacement of $1.36 \%$. These results indicate that the system works well and accurately.

In conclusion, we have successfully design a prototype of rainfall measurement using turbine system and infrared sensor that is capable of measuring weak to heavy rainfall with a very small error.

\section{REFERENCES}

[1] S.H. Soenarmo, I.A. Sadisun, and E. Saptohartono, J. Geoaplika 3, 133 (2008).

[2] D. Ren, F. Rong, L.M. Leslie, and R.E. Dickinson, Bull. Am. Meteorol. Soc. 92, 129 (2011).

[3] R.K. Das and N.R. Prakash, Int. J. Instrum. Technol. 1, 44 (2011).

[4] I.M. Erwin, Pusat Penelitian Informatika LIPI (Bandung, 2003).

[5] J. Wang, B.L. Fisher, and D.B. Wolff, J. Atmos. Ocean. Technol. 25, 43 (2008).

[6] A. Tokay, D.B. Wolff, K.R. Wolff, and P. Bashor, J. Atmos. Ocean. Technol. 20, 1460 (2003).

[7] R.A. Fulton, Weather Forecast. 14, 604 (1999).

[8] J. Wang and D.B. Wolff, J. Appl. Meteorol. Climatol. 49, 310 (2010).

[9] A. Susilo, D.R. Santoso, A. Rachmansyah, and Y. Zaika, J. Meteorol. Dan Geofis. 12, 283 (2011). 